\title{
ANALISIS EVALUASI HIGHER ORDER THINGKING SKILLS (HOTS) PADA KELAS TINGGI DI SDN KUWONHARJO 2 KECAMATAN TAKERAN KABUPATEN MAGETAN
}

\author{
Septi Aprilia, S.Pd., M.Pd.e \\ email : septi@unipma.ac.id \\ Dewi Tryanasari, S.Pd, M.Pd. \\ email: dewi@unipma.ac.id \\ Prodi PGSD Universitas PGRI Madiun (UNIPMA)
}

\begin{abstract}
Abstrak
Penelitian ini bertujuan untuk menganalisis evaluasi formatif yang dikembangkan oleh guru agar diketahui apakah bentuk evaluasi yang dikembangkan berbasis pada High Order Thinking Skills (HOTS). Subyek penelitian ini yaitu Siswa Kelas Tinggi SDN Kuwonharjo 2 Tahun Ajaran 2018/2019 UPTD Kecamatan Takeran, Kabupaten Magetan. Pendekatan penelitian yang digunakan adalah pendekatan kualitatif Deskriptif. Data penelitian ini diperoleh dari dokumen soal formatif yang dikembangkan oleh guru SDN Kuwonharjo 2. Berdasarkan keseluruhan hasil analisis evaluasi formatif menunjukkan bahwa bentuk evaluasi yang dibuat belum menunjukkan Higher Order Thinking Skills (HOTS). Semua soal masih berada pada level C1 dan C2 sehingga hal ini menjadi bahan untuk dilakukan perbaikan dalam hal perencanaan untuk membuat bentuk evaluasi minimal pada level C4.
\end{abstract}

\section{Kata Kunci :}

Evaluasi formatif, evaluasi HOTS

\section{PENDAHULUAN}

Evaluasi merupakan salah satu hal yang harus dilakukan di Sekolah Dasar untuk melihat seberapa jauh keberhasilan siswa dalam mengikuti pembelajaran. Sesuai dengan amanah permendiknas No.21 tahun 2016 tentang standar isi dan tuntutan zaman, siswa yang berhasil harus 
mampu berpikir tingkat tinggi untuk dapat menyelesaikan masalah dalam hidup. Untuk mengetahui , apakah siswa mampu berpikir kreatif dan menyelesaikan persoalan setelah mengikuti program pembelajaran tentunya diperlukan soal evaluasi yang berbobot. Dalam hal ini soal evaluasi harus berbasis pada High Order Thinking Skills (HOTS). Di lapangan telah dilakukan sosialisasi mendalam tentang hal itu namun implementasinya belum terdeskripsikan dengan baik. Sementara itu, Sekolah Dasar merupakan jenjang sekolah formal yang sangat potensial untuk dimulai dan dikembangkannya pola berfikir kritis. Hal tersebut dimaksudkan agar dapat membangun kebiasaan baik pada jenjang selanjutnya. Untuk mengukur kemampuan berfikir tingkat tinggi diperlukan instrumen yang akurat. Sayangnya akurasi instrumen pengukuran berpikir tingkat tinggi di lapangan belum terdeskripsikan dengan baik. Padahal informasi tentang akurasi instrumen evaluasi di lapangan ini sangat penting untuk mendukung proses diagnostik permasalahan evaluasi di lapangan. Untuk itu analisis tentang instrumen evaluasi di lapangan perlu dilakukan.

\section{SUBYEK DAN METODE PENELITIAN}

Subyek penelitian ini yaitu Siswa Kelas Tinggi SDN Kuwonharjo 2 Tahun Ajaran 2018/2019, dimana Sekolah tersebut terdapat di UPTD Kecamatan Takeran yang berada pada Kabupaten Magetan. Pendekatan penelitian yang digunakan adalah pendekatan kualitatif Deskriptif. Data penelitian ini diperoleh dari dokumen soal formatif yang dikembangkan oleh guru SDN Kuwonharjo 2. Triangulasi yang digunakan adalah triangulasi sumber dan metode sehingga diperoleh data yang absah.

\section{III.HASIL PENELITIAN}

Data evaluasi formatif yang diambil adalah data evaluasi formatif di kelas tinggi (Kelas 4, Kelas 5 dan Kelas 6) 
SDN Kuwonharjo 2. Dimana

setiap kelas kita ambil satu data formatif (1 tema), dan setelah dilakukan triangulasi pada setiap data evaluasi formatif maka berikut ini disajikan kesimpulan dari keseluruhan hasil triangulasi data sebagai berikut :

\section{Aspek Ketepatan Pengukuran}

Untuk Aspek ketepatan pengukuran pada evaluasi formatif dibagi kedalam tiga indikator yaitu indikator autentik, indikator bobot dan tingkat kesulitan, indikator Tematik Asessment. Yang dijelaskan sebagai berikut :

\section{a. Indikator Autentik}

Berdasarkan hasil analisis evaluasi formatif belum menunjukkan autentik assessment dimana keseluruhan bentuk soal evaluasi formatif yang dibuat masih berupa evaluasi yang standart. Ketika dianalisis dengan indikator dan tujuan pembelajaran ternyata sebagian besar bentuk evaluasi formatif yang dibuat belum mewakili kesuluruhan indikator dan tujuan pembelajaran. Sehingga diperlukan perbaikan dalam pembuatan Rencana Pembelajaran dan Bentuk evaluasi formatifnya. Agar penilaian menjadi lebih autentik yang dapat meningkatkan aspek kognitif, afektif dan psikomotorik siswa.

b. Indikator Bobot Soal dan Tingkat Kesulitan

Berdasarkan hasil analisis evaluasi formatif yang telah dilakukan bobot soal yang guru berikan belum menunjukkan tingkat kesulitan yang signifikan. Semua soal rata-rata masih berlevel $\mathrm{C} 1$ dan $\mathrm{C} 2$. Hampir semua soal mempunyai pertanyaan yang sama, yaitu tentang definisi, menyebutkan dan menjelaskan pengertian, serta belum ditemukan soal yang berisi tentang suatu analisis tertentu, atau tentang perbandingan dan menyimpulkan. Jadi tingkat kesulitan yang dihadapi oleh 
siswa tidak bervariatif, karena mempunyai bobot soal yang sama.

\section{c. Tematik Asessment}

$\begin{array}{lr}\text { Berdasarkan } & \text { hasil } \\ \text { analisis evaluasi } & \text { formatif } \\ \text { yang dilakukan } & \text { sudah } \\ \text { menunjukkan } & \text { tematik } \\ \text { assessment. Karena evaluasi } \\ \text { formatif yang di buat dan } \\ \text { kembangkan berdasarkan } \\ \text { pada kajian tema tertentu. } \\ \text { Akan tetapi untuk bentuk } \\ \text { assesmentnya perlu dilakukan } \\ \text { perbaikan. Karena semua } \\ \text { bentuk assemennya dalam } \\ \text { bobot dan } \\ \text { kesulitannya sama. }\end{array}$

\section{Aspek Kevariasian}

Untuk Aspek kevariasian pada evaluasi formatif dibagi kedalam dua indikator yaitu indikator bentuk soal dan indikator variasi bentuk soal. Yang dijelaskan sebagai berikut :

\section{a. Indikator bentuk soal}

$$
\text { Setelah dilakukan }
$$

analisis terhadap evaluasi formatif bahwa bentuk soal yang dibuat ada tiga bentuk yaitu bentuk soal pihihan ganda, bentuk soal uraian dan bentuk soal essay.

\section{b. Indikator variasi bentuk} soal

Setelah dilakukan analisis terhadap evaluasi formatif bahwa variasi bentuk soal sudah dapat dikatakan bahwa sudah bervariasi karena sudah dibuat dalam tiga bentuk yaitu bentuk soal pihihan ganda, bentuk soal uraian dan bentuk soal essay.

\section{Aspek Mengukur High}

\section{Thinking Order Skills (HOTS)}

Untuk Aspek kevariasian pada evaluasi formatif dibagi kedalam dua indikator yaitu indikator minimal level $\mathrm{C} 4$ soal dan menuntut keterampilan berfikir kritis, yang dijelaskan sebagai berikut :

\section{a. Indikator Minimal Level C4}

Berdasarkan hasil analisis yang telah dilakukan menunjukkan bahwa keseluruhan evaluasi formatif yang dibuat menunjukkan 
tingkat berfikir yang masih sama yaitu pada level $\mathrm{C} 1$ dan C2. Soal evaluasi yang di buat oleh guru masih sebatas pada pertanyaan yang sama, yaitu tentang definisi, menyebutkan dan menjelaskan pengertian, serta belum ditemukan soal yang berisi tentang suatu analisis tertentu, atau tentang perbandingan dan menyimpulkan. Tingkat berfikir siswa masih sebatas pada maksimal level C2. Jadi untuk Evaluasi yang mengarah pada Higher Order Thinking Skill (HOTS) masih belum muncul, baik pada evaluasi soal formatif dan soal sumatif.

\section{b. Indikator menuntut berfikir kritis}

Berdasarkan hasil analisis yang telah dilakukan menunjukkan bahwa keseluruhan evaluasi formatif yang dibuat menunjukkan tingkat berfikir yang masih sama yaitu pada level $\mathrm{C} 1$ dan C2. Jadi Bentuk evaluasi formatif dan evaluasi sumatif yang dibuat masih belum mengarah pada Higher Order Thinking Skill (HOTS), evaluasi belum menuntut siswa berfikir kritis. Untuk itu perlu dilakukan perbaikan baik dari segi perencanaan dalam membuat evaluasi formatif dan evaluasi sumatif agar di setiap indikatornya memunculkan tingkat keterampilan berfikir minimal pada level C4.

Berdasarkan hasil analisis keseluruhan aspek evaluasi formatif di kelas tinggi (Kelas 4, Kelas 5 dan Kelas 6) SDN Kuwonharjo 2 menunjukkan bahwa bentuk evaluasi yang dibuat belum menunjukkan Higher Order Thinking Skills (HOTS). Semua soal masih berada pada level C1 dan C2 sehingga hal ini menjadi bahan untuk dilakukan perbaikan dalam hal perencanaan untuk membuat bentuk evaluasi minimal pada level C4 sehingga kita dapat mempersiapkan generasi yang sesuai dengan amanah permendiknas No.21 tahun 2016 tentang standar isi dan tuntutan zaman, siswa yang berhasil harus mampu berpikir tingkat tinggi untuk dapat menyelesaikan masalah dalam hidup. 
Evaluasi hasil belajar berbasis Higher Order Thinking Skills (HOTS), merupakan evaluasi yang digunakan untuk mengukur kemampuan berpikir tingkat tinggi, yaitu kemampuan berpikir yang tidak sekadar mengingat (recall), menyatakan kembali (restate), atau merujuk tanpa melakukan pengolahan (recite). Akan tetapi soalsoal Higher Order Thinking Skills pada konteks asesmen mengukur kemampuan: 1) transfer satu konsep ke konsep lainnya, 2) memproses dan menerapkan informasi, 3) mencari kaitan dari berbagai informasi yang berbedabeda, 4) menggunakan informasi untuk menyelesaikan masalah, dan 5) menelaah ide dan informasi secara kritis.

Dalam Permendikbud Nomor 21 Tahun 2016 tentang Standar Isi Pendidikan Dasar dan Menengah dinyatakan secara eksplisit bahwa capaian pembelajaran (learning outcome) ranah pengetahuan mengikuti Taksonomi Bloom yang telah direvisi oleh Lorin Anderson dan David Krathwohl (2001) terdiri atas kemampuan: mengetahui (knowing-C1), memahami
(understanding-C2), menerapkan (aplying-C3), menganalisis (analyzing-C4), mengevaluasi (evaluating-C5), dan mengkreasi (creating-C6). Soal-soal HOTS pada umumnya mengukur kemampuan pada ranah menganalisis (analyzing$\mathrm{C} 4)$, mengevaluasi (evaluating-C5), dan mengkreasi (creating-C6).

\section{KESIMPULAN}

Berdasarkan hasil analisis di SDN evaluasi formatif di kelas tinggi (Kelas 4, Kelas 5 dan Kelas 6) SDN Kuwonharjo 2 menunjukkan bahwa bentuk evaluasi yang dibuat belum menunjukkan Higher Order Thinking Skills (HOTS). Semua soal masih berada pada level $\mathrm{C} 1$ dan $\mathrm{C} 2$ sehingga hal ini menjadi bahan untuk dilakukan perbaikan dalam hal perencanaan untuk membuat bentuk evaluasi minimal pada level C4.

\section{DAFTAR PUSTAKA}

Basuki, I. dkk.. (2015). Assmen Pembelajaran.Bandung : Remaja Rosdakarya

Devi, P. K. (13 Mei 2012).
Pengembangan
Order Thinking Skill" 
Pembelajaran IPA SMP/MTs. Diambiltanggal 23 Juni 2013, dari http://p4tkipa.net/datajurnal/HOTs.Poppy.pdf.

Griffin, P., dan Nix, P. 1991. Educational Assessment and Reporting. Sydney: Harcout Brace Javanovich Publisher.

Kirkpatrick, D. L. 1998. Evaluating Training Programs: The Four

Krathwohl. D.R, (2002) A Revision of Blom's Taxonomy: An Overview. Journa: collefe of Educarion, The Ohio State University.Levels. San Francisco: Berrett-Koehler Publisher, Inc.

Mardapi, D. 2000. Evaluasi Pendidikan. Makalah disajikan dalam Konvensi Pendidikan Nasional, Universitas Negeri Jakarta,

Oriondo, L. L., dan Antonio, E. M. D. $\quad 1998 . \quad$ Evaluating Educational Outcomes (Test, Measurment, and Evaluation). Florentino St: Rex Printing Company.

Stark, J. S., dan Thomas, A. 1994. Assessment and Program Evaluation. Needham Heights: Simon \& Schuster Custom Publishing.

Sudjana, N., dan Ibrahim. 2004. Penelitian dan Penilaian Pendidikan. Bandung:

Sinar Baru Algesindo. 